\title{
CONTROLE DE PLANTAS DANINHAS EM FEIJÃO NUM SISTEMA DE ROTAÇÃO DE CULTURAS EM PLANTIO DIRETO'
}

\author{
BENEDITO N. RODRIGUES ${ }^{2}$ e TELMA PASSINI ${ }^{3}$
}

\begin{abstract}
O objetivo deste trabalho foi selecionar culturas de inverno para formação de cobertura morta que reduza a população de plantas daninhas na cultura do feijão (Phaseolus vulgaris). Ocupou-se o terreno durante o ano todo, com a sucessão, em plantio direto, de pousio ou cultura de inverno/feijão/cultura para silagem, estudando-se três modalidades de controle de plantas daninhas na cultura do feijão. A

This study was undertaken to select winter crops for mulching to reduce the weed infestation and to lower weed control costs in bean (Phaseolus vulgaris) production. The soil was kept covered all the year under no-tillage with a sequence of a winter crop or fallow/beans/silage crop. Three weed control methods for beans were studied. After two
\end{abstract}

RESUMO maior renda líquida acumulada após duas safras foi obtida com feijão semeado sobre palha de aveia-preta e controle de plantas daninhas com um graminicida pré-emergente, complementando-se com capinas, quando necessário.

Palavras-chave: Phaseolus vulgaris, culturas de inverno, silagem, cobertura morta, rentabilidade.

\section{ABSTRACT \\ Weed control in beans in a no-tillage crop rotation system}

\section{INTRODUÇÃO}

O sistema de plantio direto tem sido utilizado com sucesso pelos agricultores, notadamente nas culturas de soja (Glycine max) e de milho (Zea mays). A utilização de uma cultura de inverno adequada, seus restos vegetais ou coberturas mortas, influem na infestação das culturas de verão subsequentes, liberando compostos alelopáticos que podem inibira germinação de algumas espécies de plantas daninhas (Almeida, 1988; Almeida \& Rodrigues, 1985) permitindo a redução do uso de herbicidas ou de outros meios de controle (Almeida, 1991; Almeida et al., 1984).

A cultura do feijão tem sido conduzida principalmente no sistema convencional (Almeida et al., 1983; Rodrigues et

\footnotetext{
1 Recebido para publicação em 20/09/94 e na forma revisada em 29/04/95

2 Ene Agra, PhD, Pesquisador, IAPAR, Área de Filotecnia, Caixa Posta1 1331, Londrina, PR 86001-970

3 Ene Agra, MSc, Pesquisadora, IAPAR, Área de Fitotecnia, Caixa Postal 1331,

Londrina, PR 86001-970
}

complete crop sequences, the highest total net income was obtained with the beans directly drilled on the black oats (A vena strigosa) mulching, spraying a pre-emergence grasskiller plus hoeing when needed.

Additional index words: Phaseolus vulgaris, winter crops, silage, mulch, net income.

al., 1989). Resultados preliminares, no sistema de plantio direto, indicaram que, entre as culturas de inverno, o centeio (Secale cereale) proporcionou a maior quantidade de cobertura morta sobre o terreno, permitindo o maior controle de plantas daninhas na cultura do feijão que se instalou a seguir (Rodrigues \& Almeida, 1985/86).

O objetivo deste trabalho foi o de identificar culturas de inverno que devem preceder o feijão, para manter o solo coberto durante a maior parte do ano, reduzir a população de plantas daninhas e o custo de seu controle, proporcionando maior renda ao agricultor, numa rotação de culturas de inverno/feijão das águas/milho ou sorgo para silagem.

\section{MATERIAL E MÉTODOS}

O experimento foi conduzido em Arapoti-PR, no período de junho de 1986 a abril de 1988. 0 local do experimento apresenta relevo suave ondulado e solo classificado como Latossolo Vermelho-escuro álico, horizonte A proemi- 
nente, textura argilosa, fase floresta subtropical perenifolia. A análise física revelou uma composição de $45 \%$ de argila, $9 \%$ de silte e $46 \%$ de areia e, a análise química, $\mathrm{pH}\left(\mathrm{CaCl}_{2}\right)$ de 5,6 e teores de $\mathrm{Ca}^{+2}=4,45, \mathrm{Mg}^{+2}=1,77$ e $\mathrm{K}^{+}=0,47$ expressos em m.e. $/ 100 \mathrm{~g}$ de solo; $\mathrm{C}=2,26 \%$ e $\mathrm{P}=15,3 \mathrm{ppm}$. $\mathrm{O}$ clima do local é classificado como $\mathrm{Cfb}$, subtropical úmido, mesotérmico, veres frescos, geadas severas, frequentes, sem estação seca, temperatura média das máximas de $24-25^{\circ} \mathrm{C}$ e temperatura média das mínimas de $12-13^{\circ} \mathrm{C}$ (IAPAR, 1978).

$\mathrm{O}$ delineamento experimental adotado foi o de blocos ao acaso, com tratamentos em parcelas subdivididas, com três repetições. As parcelas, de 9,0 x 15,0m, foram constituídas por três subparcelas de $3,0 \times 15 \mathrm{~m}$. Os tratamentos em parcelas foram pousio, trigo (Triticum aestivum), aveia-preta (Avena strigosa), centeio (Secale cereale), ervilhaca (Vicia sativa) e tremoço-azul (Lupinus angustifolius) no inverno. Os tratamentos emsubparcelas foram as modalidades de controle de plantas daninhas na cultura do feijão: 1) capinas; 2) herbicida pré-emergente, seguido de capinas, quando necessário; 3) herbicida(s) pós-emergente(s). O herbicida préemergente utilizado foi metolachlor a $1,8 \mathrm{~kg}$ i.a.ha" ${ }^{1}$. O herbicida pós-emergente utilizado no primeiro ano foi sethoxydim a $0,23 \mathrm{~kg}$ i.a. ha' ${ }^{1}$ seguido de uma aplicação da mistura de bentazon + acetato de dinoseb a 0,48 + 0,24 kg i.a. ha' ${ }^{1}$ e, no segundo ano, a formulação bentazon + paraquat a $(0,12+$ $0,075) \mathrm{kg}$ i.a. ha' 1 .

O experimento teve início em junho de 1986 com as culturas de inverno, semeadas após preparo convencional do solo, no espaçamento de $17 \mathrm{~cm}$ e profundidade de $3-4 \mathrm{~cm}$, sem adubação de base. A formação da cobertura morta foi feita com rolo-faca, na segunda quinzena de setembro. $\mathrm{O}$ feijão, cv. 'Carioca', foi semeado no espaçamento de $50 \mathrm{~cm}$, profundidade de $3-4 \mathrm{~cm}$, colocando-se 15 a 20 sementes por metro linear. A adubação, no sulco de semeadura, foi feita com $200 \mathrm{~kg} \mathrm{ha}^{\prime 1}$ de $05-25-25$, no primeiro ano e $200 \mathrm{~kg}$ ha'1 de 00-30-10, no segundo. Após a primeira safra de feijão, o sorgo, cv. AG 2001, foi semeado no espaçamento de $53 \mathrm{~cm}$, utilizando-se 30 sementes por metro linear. No ano seguinte, o milho, cv. Cargill 511, foi semeado no espaçamento de $90 \mathrm{~cm}$, profundidade de $3-4 \mathrm{~cm}$, colocando-se 7 a 9 sementes por metro linear. Essas culturas foram destinadas à produção de silagem. Os herbicidas, na cultura do feijão, foram aplicados com equipamento costal de pressão constante, munido de barra com 6 bicos espaçados de $50 \mathrm{~cm}$, permitindo a cobertura de uma faixa de $3,0 \mathrm{~m}$ de largura. As aplicações dos herbicidas de manejo foram feitas com equipamento tratorizado, utilizando-se glyphosate + 2,4-D $(0,72+0,6) \mathrm{kg}$.ha' 1 , antes da semeadura das culturas de inverno e das culturas destinadas a silagem e, (paraquat + diuron) a $(0,3+0,15) \mathrm{kg}$ ha' $^{1}$ antes da semeadura do feijão. Nas culturas de inverno, devido a baixa infestação, não se fez controle de ervas. Nas culturas destinadas à silagem, fez-se uma capina manual.

A porcentagem de solo coberto pela palha da cultura de inverno foi avaliada visualmente 20 dias depois da semeadura do feijão; a fitotoxicidade dos herbicidas ao feijoeiro, aos 20 e 40 dias depois de sua semeadura e, o controle de plantas daninhas, aos 40 dias. Estas duas variáveis foram avaliadas segundo uma escala de notas de 0-100, em que zero representa controle nulo de plantas daninhas sem efeito fitotóxico para a cultura e o valor 100 representa controle total de plantas daninhas e morte da cultura. Calculou-se a produtividade de feijão $\left(\mathrm{kg} \cdot \mathrm{ha}^{-1}\right)$ e silagem $\left(\mathrm{t} \cdot \mathrm{ha}^{-1}\right)$. Dentro de cada ano agrícola, foram tomados os custos de operações, insumos e produção para fins de cálculos econômicos.

Os dados pluviométricos e o cronograma de atividades são apresentados, respectivamente, nas tabelas 1 e 2 .

\section{TABELA 1 - Dados pluviométricos $(\mathrm{mm})$ registrados em} Arapoti, PR, no período de 1986 a 1988.

\begin{tabular}{l|r|r|r}
\hline \multirow{2}{*}{ Mês } & \multicolumn{3}{|c}{ Ano } \\
\cline { 2 - 4 } & $\mathbf{1 9 8 6}$ & $\mathbf{1 9 8 7}$ & $\mathbf{1 9 8 8}$ \\
\hline Janeiro & 174,9 & 170,6 & 87,9 \\
Fevereiro & 244,6 & 284,4 & 132,8 \\
Março & 199,8 & 35,4 & 127,3 \\
Abril & 148,0 & 52,2 & 99,6 \\
Maio & 193,8 & 287,6 & 300,1 \\
Junho & 1,5 & 164,0 & 59,4 \\
Julho & 21,2 & 56,9 & 0 \\
Agosto & 175,0 & 31,9 & 0 \\
Setembro & 59,2 & 117,1 & 57,4 \\
Outubro & 71,7 & 99,5 & 109,2 \\
Novembro & 107,6 & 118,7 & 39,9 \\
Dezembro & 286,3 & 110,2 & 184,0 \\
\hline Total & 1683,6 & 1528,5 & 1197,6 \\
\hline
\end{tabular}

Para a avaliação dos resultados, os dados foram submetidos à análise de variância e, as médias, à comparação pelo teste de Tukey a $5 \%$.

\section{RESULTADOS E DISCUSSÃO}

Na safra 86/87, 20 dias após a semeadura do feijão, as maiores coberturas do solo eram proporcionadas pela palha das culturas de trigo, aveia e centeio (Tabela 3), confirmando resultados anteriores (Almeida \& Rodrigues, 1985). No ano seguinte, além destas, a palha de ervilhaca também proporcionou boa cobertura do solo. A palha de tremoço sofreu rápida decomposição, não diferindo das parcelas em pousio.

Nas duas safras, os herbicidas utilizados não causaram fitotoxicidade visível ao feijão e por isso os dados não são apresentados.

As espécies de plantas daninhas que ocorreram no experimento foram capim-marmelada (Brachiaria plantaginea), guanxuma (Sida rhombifolia) e nabiça (Raphanus raphanistrum). Aos 40 dias após a semeadura do feijão, nas duas safras, os melhores níveis de controle de Brachiaria plantaginea foram observados nas coberturas de trigo, aveia e centeio (Tabela 4). Não houve diferença entre as modalidades de controle, nas coberturas de aveia e ervilhaca. $\mathrm{Na}$ safra 1986/87, em cobertura de trigo, o uso exclusivo de capinas foi menos eficiente que o uso de herbicidas pré ou pós-emergentes. Em cobertura de centeio, tremoço e pousio, o melhor controle foi proporcionado pelo uso de pós-emergentes. Em 1987/88, de forma geral, os níveis de controle de $B$. plantaginea foram inferiores em todos os tratamentos e 
TABELA 2 - Cronograma das atividades desenvolvidas na área experimental no período de 1986 a 1988, Arapoti, PR.

\begin{tabular}{|c|c|c|}
\hline \multicolumn{2}{|c|}{ Ano agrícola } & \multirow{2}{*}{ Atividades } \\
\hline $1986 / 87$ & $1987 / 88$ & \\
\hline- & $21 / 04 / 87$ & $\begin{array}{l}\text { Início das atividades do ano agrícola 1987/88; } \\
\text { aplicação de herbicidas de manejo. }\end{array}$ \\
\hline- & $28 / 04 / 87$ & Semeadura das culturas de inverno (plantio direto). \\
\hline 04/06/86 & - & $\begin{array}{l}\text { Início das atividades do ano agrícola } 1986 / 87 \\
\text { semeadura das culturas de inverno (preparo convencional do solo). }\end{array}$ \\
\hline $02 / 09 / 86$ & $01 / 09 / 87$ & Formaçâo da cobertura morta com rolo faca. \\
\hline $16 / 09 / 86$ & $15 / 09 / 87$ & Aplicação de herbicidas de manejo. \\
\hline $25 / 09 / 86$ & $16 / 09 / 87$ & Semeadura do feijẩo em plantio direto/aplicação do pré-emergente. \\
\hline $15 / 10 / 86$ & $06 / 10 / 87$ & Avaliação visual e $1^{2}$ capina \\
\hline $25 / 10 / 86$ & $26 / 10 / 87$ & Aplicaçẫo dos pós-emergentes (30 DDS). \\
\hline $04 / 11 / 86$ & $31 / 10 / 87$ & Segunda capina do feijäo ( 40 e 45 DDS \\
\hline 07/09/87 & $22 / 12 / 87$ & Colheita do feijāo e aplicação de herbicidas de manejo. \\
\hline- & $23 / 12 / 87$ & Semeadura do milho em plantio direto. \\
\hline $16 / 01 / 87$ & - & Semeadura do sorgo em plantio direto. \\
\hline $23 / 01 / 87$ & - & Capina do sorgo. \\
\hline- & $12 / 01 / 88$ & Capina do milho. \\
\hline $01 / 04 / 87$ & - & Corte do sorgo para silagem. \\
\hline- & $07 / 04 / 88$ & Corte do milho para silagem. \\
\hline
\end{tabular}

TABELA 3 - Cobertura do solo pela palha das culturas de inverno aos 20 dias após a semeadura do feijajo. Arapoti, PR ${ }^{1}$.

\begin{tabular}{l|c|c|c|c|c|c}
\hline \multirow{2}{*}{$\begin{array}{c}\text { Culturas de } \\
\text { inverno }\end{array}$} & \multicolumn{3}{c}{$\begin{array}{c}\text { 1986/87 } \\
\text { Modalidades de controle }\end{array}$} & \multicolumn{3}{c}{$\begin{array}{c}1987 / 88 \\
\text { Modalidades de controle }\end{array}$} \\
\cline { 2 - 7 } & Cap & PE+Cap & PO & Cap & PE+Cap & PO \\
\hline trigo & A & A & A & A & A & A \\
& 45 a & 47 a & 48 ab & 45 bc & 47 a & 39 b \\
aveia & A & A & A & A & A & A \\
& 38 a & $34 \mathrm{~b}$ & $36 \mathrm{~b}$ & $46 \mathrm{bc}$ & $45 \mathrm{a}$ & $41 \mathrm{~b}$ \\
centeio & $\mathrm{A}$ & $\mathrm{A}$ & $\mathrm{A}$ & $\mathrm{A}$ & $\mathrm{A}$ & $\mathrm{A}$ \\
& $39 \mathrm{a}$ & $44 \mathrm{a}$ & $43 \mathrm{ab}$ & $50 \mathrm{~b}$ & $49 \mathrm{a}$ & $46 \mathrm{~b}$ \\
ervilhaca & $\mathrm{A}$ & $\mathrm{A}$ & $\mathrm{A}$ & $\mathrm{A}$ & $\mathrm{B}$ & $\mathrm{AB}$ \\
& $24 \mathrm{~b}$ & $24 \mathrm{c}$ & $20 \mathrm{c}$ & $63 \mathrm{a}$ & $49 \mathrm{a}$ & $58 \mathrm{a}$ \\
tremoço & $\mathrm{A}$ & $\mathrm{A}$ & $\mathrm{A}$ & $\mathrm{A}$ & $\mathrm{AB}$ & $\mathrm{B}$ \\
& $13 \mathrm{c}$ & $15 \mathrm{~d}$ & $14 \mathrm{~d}$ & $36 \mathrm{c}$ & $30 \mathrm{~b}$ & $22 \mathrm{c}$ \\
pousio & $\mathrm{A}$ & $\mathrm{A}$ & $\mathrm{A}$ & $\mathrm{A}$ & $\mathrm{A}$ & $\mathrm{A}$ \\
& $12 \mathrm{c}$ & $13 \mathrm{~d}$ & $10 \mathrm{~d}$ & $14 \mathrm{~d}$ & $11 \mathrm{c}$ & $15 \mathrm{c}$ \\
\hline
\end{tabular}

1 Médias seguidas da mesma letra, não diferem entre si pelo teste de Tukey ao nível de $5 \%$ de probabilidade, sendo que, letras maiúsculas sobre os números, referem-se a efeitos de subtratamentos (modalidades de controle) dentro de cada tratamento (culturas de inverno) ou comparaçāo na horizontal e, letras minúsculas ao lado dos números, referem-se a efeitos de tratamentos dentro de cada subtratamento, ou comparação na vertical.

$2 \mathrm{Cap}=$ capinas; $\mathrm{PE}=$ berbicida pré-emergente; $\mathrm{PO}=$ herbicida pós-emergente. 
TABELA 4 - Controle de Brachiaria plantaginea aos 40 dias após a semeadura do feijāo sobre cobertura morta de culturas de inverno. Arapoti, $\mathbf{P R}^{1}$.

\begin{tabular}{l|c|c|c|c|c|c}
\hline \multirow{2}{*}{$\begin{array}{c}\text { Culturas de } \\
\text { inverno }\end{array}$} & \multicolumn{3}{c|}{$\begin{array}{c}\text { 1986/87 } \\
\text { Modalidades de controle }\end{array}$} & \multicolumn{3}{c}{$\begin{array}{c}\text { 1987/88 } \\
\text { Modalidades de controle }\end{array}$} \\
\cline { 2 - 7 } & Cap & PE+Cap & PO & Cap & PE+Cap & PO \\
\hline trigo & $\mathrm{B}$ & $\mathrm{A}$ & $\mathrm{A}$ & $\mathrm{B}$ & $\mathrm{AB}$ & $\mathrm{A}$ \\
& $78 \mathrm{bc}$ & $94 \mathrm{a}$ & $92 \mathrm{a}$ & $72 \mathrm{bc}$ & $82 \mathrm{ab}$ & $92 \mathrm{a}$ \\
aveia & $\mathrm{A}$ & $\mathrm{A}$ & $\mathrm{A}$ & $\mathrm{A}$ & $\mathrm{A}$ & $\mathrm{A}$ \\
& $90 \mathrm{a}$ & $90 \mathrm{ab}$ & $90 \mathrm{ab}$ & $87 \mathrm{a}$ & $87 \mathrm{a}$ & $92 \mathrm{a}$ \\
centeio & $\mathrm{B}$ & $\mathrm{B}$ & $\mathrm{A}$ & $\mathrm{B}$ & $\mathrm{A}$ & $\mathrm{AB}$ \\
& $85 \mathrm{ab}$ & $87 \mathrm{~b}$ & $94 \mathrm{a}$ & $75 \mathrm{ab}$ & $90 \mathrm{a}$ & $82 \mathrm{ab}$ \\
ervilhaca & $\mathrm{A}$ & $\mathrm{A}$ & $\mathrm{A}$ & $\mathrm{A}$ & $\mathrm{A}$ & $\mathrm{A}$ \\
& $69 \mathrm{c}$ & $77 \mathrm{c}$ & $75 \mathrm{c}$ & $58 \mathrm{c}$ & $69 \mathrm{bc}$ & $68 \mathrm{~b}$ \\
tremoço & $\mathrm{B}$ & $\mathrm{AB}$ & $\mathrm{A}$ & $\mathrm{C}$ & $\mathrm{B}$ & $\mathrm{A}$ \\
& $73 \mathrm{c}$ & $79 \mathrm{~d}$ & $83 \mathrm{bc}$ & $35 \mathrm{~d}$ & $58 \mathrm{c}$ & $87 \mathrm{a}$ \\
pousio & $\mathrm{B}$ & $\mathrm{B}$ & $\mathrm{A}$ & $\mathrm{C}$ & $\mathrm{A}$ & $\mathrm{B}$ \\
& $78 \mathrm{bc}$ & $78 \mathrm{c}$ & $94 \mathrm{a}$ & $35 \mathrm{~d}$ & $82 \mathrm{ab}$ & $52 \mathrm{c}$ \\
\hline
\end{tabular}

${ }^{1}$ Médias seguidas da mesma letra, não diferem entre si pelo teste de Tukey ao nível de $5 \%$ de probabilidade, sendo que, letras maiúsculas sobre os números, referem-se a efeitos de subtratamentos (modalidades de controle) dentro de cada tratamento (culturas de inverno) ou comparaçâo na horizontal e, letras minúsculas ao lado dos números, referem-se a efeitos de tratamentos dentro de cada subtratamento, ou comparaçāo na vertical.

${ }^{2} \mathrm{Cap}=$ capinas; $\mathrm{PE}=$ herbicida pré-emergente; $\mathrm{PO}=$ herbicida pós-emergente.

estiveram abaixo do aceitável nas coberturas de ervilhaca, tremoço e pousio. Isso pode ser devido à produção de sementes de plantas daninhas, aumentando o banco de sementes no terreno, o que dificulta o controle. Este resultado foi confirmado posteriormente por Skóra Neto (1993). No pousio, o melhor controle foi proporcionado pelo uso do graminicida pré-emergente seguido de capinas e, na cobertura de tremoço, pelo uso do pós-emergente.
A maioria dos tratamentos apresentou bom controle de S.rhombifolia (Tabela 5). Devido à pequena cobertura do solo proporcionada pelo tremoço e pousio, o controle com herbicidas pós-emergentes, que apresentava os menores níveis na safra 1986/87, apresentou níveis ainda mais baixos na safra seguinte. Em 1987/88, o uso de herbicidas pósemergentes após trigo foi deficiente no controle de $S$. rhombifolia. Nesta última safra, os controles com capinas e her-

TABELA 5 - Controle de Sida rhombifolia aos $\mathbf{4 0}$ dias após a semeadura do feijẩo sobre cobertura morta de culturas de inverno. Arapoti, $\mathbf{P R}$.

\begin{tabular}{l|c|c|c|c|c|c}
\hline \multirow{2}{*}{$\begin{array}{c}\text { Culturas de } \\
\text { inverno }\end{array}$} & \multicolumn{3}{c|}{$\begin{array}{c}1986 / 87 \\
\text { Modalidades de controle }\end{array}$} & \multicolumn{3}{c}{$\begin{array}{c}1987 / 88 \\
\text { Modalidades de controle }\end{array}$} \\
\cline { 2 - 7 } & $\mathrm{Cap}$ & PE+Cap & PO & Cap & PE+Cap & PO \\
\hline trigo & $\mathrm{A}$ & $\mathrm{A}$ & $\mathrm{A}$ & $\mathrm{A}$ & $\mathrm{A}$ & $\mathrm{B}$ \\
& $85 \mathrm{a}$ & $92 \mathrm{a}$ & $88 \mathrm{ab}$ & $82 \mathrm{ab}$ & $82 \mathrm{a}$ & $53 \mathrm{c}$ \\
aveia & $\mathrm{A}$ & $\mathrm{A}$ & $\mathrm{A}$ & $\mathrm{A}$ & $\mathrm{AB}$ & $\mathrm{B}$ \\
& $89 \mathrm{a}$ & $87 \mathrm{ab}$ & $84 \mathrm{bc}$ & $87 \mathrm{a}$ & $84 \mathrm{a}$ & $77 \mathrm{a}$ \\
centeio & $\mathrm{B}$ & $\mathrm{AB}$ & $\mathrm{A}$ & $\mathrm{A}$ & $\mathrm{A}$ & $\mathrm{B}$ \\
& $87 \mathrm{a}$ & $90 \mathrm{a}$ & $94 \mathrm{a}$ & $87 \mathrm{a}$ & $82 \mathrm{a}$ & $70 \mathrm{ab}$ \\
ervilhaca & $\mathrm{A}$ & $\mathrm{A}$ & $\mathrm{A}$ & $\mathrm{A}$ & $\mathrm{A}$ & $\mathrm{A}$ \\
& $82 \mathrm{a}$ & $87 \mathrm{ab}$ & $83 \mathrm{a}$ & $85 \mathrm{a}$ & $80 \mathrm{ab}$ & $79 \mathrm{a}$ \\
tremoço & $\mathrm{A}$ & $\mathrm{A}$ & $\mathrm{A}$ & $\mathrm{A}$ & $\mathrm{A}$ & $\mathrm{B}$ \\
& $83 \mathrm{a}$ & $82 \mathrm{~b}$ & $78 \mathrm{c}$ & $73 \mathrm{~b}$ & $72 \mathrm{~b}$ & $58 \mathrm{c}$ \\
pousio & $\mathrm{A}$ & $\mathrm{AB}$ & $\mathrm{B}$ & $\mathrm{A}$ & $\mathrm{A}$ & $\mathrm{B}$ \\
& $85 \mathrm{a}$ & $80 \mathrm{~b}$ & $77 \mathrm{c}$ & $75 \mathrm{~b}$ & $77 \mathrm{ab}$ & $63 \mathrm{bc}$ \\
\hline
\end{tabular}

${ }^{1}$ Médias seguidas da mesma letra, năo diferem entre si pelo teste de Tukey ao nível de 5\% de probabilidade, sendo que, letras maiúsculas sobre os números, referem-se a efeitos de subtratamentos (modalidades de controle) dentro de cada tratamento (culturas de inverno) ou comparaçăo na horizontal e, letras minúsculas ao lado dos números, referem-se a efeitos de tratamentos dentro de cada subtratamento, ou comparaçáo na vertical.

${ }^{2} \mathrm{Cap}=$ capinas; $\mathrm{PE}=$ herbicida pré-emergente; $\mathrm{PO}=$ herbicida pós-emergente. 
bicida pré-emergente + capina foram semelhantes entre si e superiores aos herbicidas pós-emergentes.

As três modalidades de controle foram ineficientes em R. raphanistrum, quando o feijão foi implantado após pousio (Tabela 6). A produção de sementes pelas plantas remanescentes do primeiro ano acentuou, no segundo ano, a diferença entre o pousio e as demais coberturas mortas. Na primeira safra, o melhor controle desta espécie foi obtido nas cobertu ras mortas de trigo e ervilhaca, com herbicida pré-emergente + capina. Na safra seguinte, o maior valor foi obtido com capina na cobertura morta de centeio.

Em valores absolutos, as maiores produtividades de feijão foram obtidas, no primeiro ano, nas coberturas mortas de aveia e trigo com herbicida pré-emergente + capina. No ano seguinte, a maior produtividade foi conseguida no pousio com capinas (Tabela 7).

TABELA 6 - Controle de Raphanus raphanistrum aos 40 dias após a semeadura do feijáo sobre cobertura morta de culturas de inverno. Arapoti, PR 1 .

\begin{tabular}{|c|c|c|c|c|c|c|}
\hline \multirow{2}{*}{$\begin{array}{l}\text { Culturas de } \\
\text { inverno }\end{array}$} & \multicolumn{3}{|c|}{$\begin{array}{c}1986 / 87 \\
\text { Modalidades de controle }^{2}\end{array}$} & \multicolumn{3}{|c|}{$\begin{array}{c}1987 / 88 \\
\text { Modalidades de controle }\end{array}$} \\
\hline & Cap & $\mathrm{PE}+\mathrm{Cap}$ & PO & Cap & PE+Cap & PO \\
\hline trigo & $\begin{array}{c}\text { A } \\
89 \mathrm{ab}\end{array}$ & $\begin{array}{c}\text { A } \\
94 \text { a }\end{array}$ & $\begin{array}{c}\text { A } \\
89 \mathrm{ab}\end{array}$ & $\begin{array}{c}\text { A } \\
84 \text { bc }\end{array}$ & $\begin{array}{c}\text { A } \\
84 \text { a }\end{array}$ & $\begin{array}{c}\mathrm{B} \\
70 \mathrm{~b}\end{array}$ \\
\hline aveia & $\begin{array}{c}\text { A } \\
93 \text { a }\end{array}$ & $\frac{\mathrm{AB}}{87 \mathrm{~b}}$ & $\begin{array}{l}\text { B } \\
84 \mathrm{bc}\end{array}$ & $\begin{array}{l}\text { A } \\
87 \mathrm{ab}\end{array}$ & $\begin{array}{c}\text { A } \\
84 \text { a }\end{array}$ & $\begin{array}{c}\mathrm{A} \\
82 \mathrm{a}\end{array}$ \\
\hline centeio & $\begin{array}{c}\text { B } \\
82 \mathrm{~b}\end{array}$ & $\begin{array}{l}\mathrm{AB} \\
90 \mathrm{ab}\end{array}$ & $\begin{array}{c}\text { A } \\
93 \text { a }\end{array}$ & $\begin{array}{l}\text { A } \\
92 \text { a }\end{array}$ & $\begin{array}{l}\text { B } \\
82 \mathrm{ab}\end{array}$ & $\begin{array}{c}\mathrm{C} \\
70 \mathrm{~b}\end{array}$ \\
\hline ervilhaca & $\begin{array}{l}\text { A } \\
87 \mathrm{ab}\end{array}$ & $\begin{array}{l}\text { A } \\
94 \text { a }\end{array}$ & $\begin{array}{l}\text { B } \\
77 \mathrm{~cd}\end{array}$ & $\begin{array}{c}\text { A } \\
77 \mathrm{c}\end{array}$ & $\begin{array}{c}\text { A } \\
85 \text { a }\end{array}$ & $\begin{array}{c}\mathrm{A} \\
75 \mathrm{ab}\end{array}$ \\
\hline tremoço & $\begin{array}{l}\text { A } \\
87 \mathrm{ab}\end{array}$ & $\begin{array}{l}\text { A } \\
88 \mathrm{ab}\end{array}$ & $\begin{array}{l}\text { A } \\
85 \text { abc }\end{array}$ & $\begin{array}{c}\text { A } \\
74 \mathrm{c}\end{array}$ & $\begin{array}{c}\mathrm{A} \\
72 \mathrm{~b}\end{array}$ & $\begin{array}{c}A \\
68 b\end{array}$ \\
\hline pousio & $\begin{array}{c}\mathrm{A} \\
57 \mathrm{c}\end{array}$ & $\begin{array}{c}A \\
64 c\end{array}$ & $\frac{A}{65 d}$ & $\begin{array}{c}\mathrm{A} \\
17 \mathrm{~d}\end{array}$ & $\begin{array}{c}A \\
21 \mathrm{c}\end{array}$ & $\begin{array}{c}\text { A } \\
21 \mathrm{c}\end{array}$ \\
\hline
\end{tabular}

1 Médias seguidas da mesma letra, nāo diferem entre si pelo teste de Tukey ao nível de 5\% de probabilidade, sendo que, letras maiúsculas sobre os números, referem-se a efeitos de subtratamentos (modalidades de controle) dentro de cada tratamento (culturas de inverno) ou comparaçāo na borizontal e, letras minúsculas ao lado dos números, referem-se a efeitos de tratamentos dentro de cada subtratamento, ou comparaçăo na vertical.

2 Cap= capinas; $\mathrm{PE}=$ herbicida pré-emergente; $\mathrm{PO}=$ herbicida pós-emergente.

TABELA 7 - Produtividade de feijáo (kg.ha ${ }^{-1}$ a 14\% U) no sistema de plantio direto em diferentes coberturasmortas. Arapoti, PR ${ }^{1}$.

\begin{tabular}{l|c|c|c|c|c|c}
\hline \multirow{2}{*}{$\begin{array}{c}\text { Culturas de } \\
\text { inverno }\end{array}$} & \multicolumn{3}{|c|}{$\begin{array}{c}\text { 1986/87 } \\
\text { Modalidades de controle }\end{array}$} & \multicolumn{3}{c}{ 1987/88 } \\
Modalidades de controle \\
\cline { 2 - 7 } & Cap & PE+Cap & PO & Cap & PE+Cap & PO \\
\hline trigo & $\mathrm{A}$ & $\mathrm{A}$ & $\mathrm{A}$ & $\mathrm{AB}$ & $\mathrm{A}$ & $\mathrm{B}$ \\
& $1857 \mathrm{a}$ & $2086 \mathrm{ab}$ & $1862 \mathrm{a}$ & $876 \mathrm{~b}$ & $1298 \mathrm{a}$ & $623 \mathrm{a}$ \\
aveia & $\mathrm{B}$ & $\mathrm{A}$ & $\mathrm{AB}$ & $\mathrm{A}$ & $\mathrm{A}$ & $\mathrm{A}$ \\
& $1807 \mathrm{a}$ & $2593 \mathrm{a}$ & $2051 \mathrm{a}$ & $1147 \mathrm{ab}$ & $1224 \mathrm{a}$ & $990 \mathrm{a}$ \\
centeio & $\mathrm{A}$ & $\mathrm{A}$ & $\mathrm{A}$ & $\mathrm{B}$ & $\mathrm{A}$ & $\mathrm{B}$ \\
& $1517 \mathrm{a}$ & $1165 \mathrm{c}$ & $1720 \mathrm{a}$ & $715 \mathrm{~b}$ & $1291 \mathrm{a}$ & 751 a \\
ervilhacam & $\mathrm{A}$ & $\mathrm{A}$ & $\mathrm{A}$ & $\mathrm{A}$ & $\mathrm{A}$ & $\mathrm{A}$ \\
& $1744 \mathrm{a}$ & $1859 \mathrm{abc}$ & $1609 \mathrm{a}$ & $920 \mathrm{~b}$ & $1091 \mathrm{a}$ & $878 \mathrm{a}$ \\
tremoço & $\mathrm{A}$ & $\mathrm{A}$ & $\mathrm{A}$ & $\mathrm{A}$ & $\mathrm{AB}$ & $\mathrm{A}$ \\
& $1541 \mathrm{a}$ & $2015 \mathrm{ab}$ & $1735 \mathrm{a}$ & $1419 \mathrm{a}$ & $1207 \mathrm{a}$ & $737 \mathrm{a}$ \\
pousio & $\mathrm{A}$ & $\mathrm{A}$ & $\mathrm{A}$ & $\mathrm{A}$ & $\mathrm{A}$ & $\mathrm{B}$ \\
& $1739 \mathrm{a}$ & $1771 \mathrm{bc}$ & $1535 \mathrm{a}$ & $1430 \mathrm{a}$ & $1178 \mathrm{a}$ & 619 a \\
\hline
\end{tabular}

${ }^{1}$ Médias seguidas da mesma letra, náo diferem entre si pelo teste de Tukey ao nível de $5 \%$ de probabilidade, sendo que, letras maiúsculas sobre os números, referem-se a efeitos de subtratamentos (modalidades de controle) dentro de cada tratamento (culturas de inverno) ou comparaçăo na horizontal e, letras minúsculas ao lado dos números, referem-se a efeitos de tratamentos dentro de cada subtratamento, ou comparaçáo na vertical.

${ }^{2} \mathrm{Cap}=$ capinas; $\mathrm{PE}=$ herbicida pré-emergente; $\mathrm{PO}=$ herbicida pós-emergente. 
Controle de nlantac daninhac em feiião

As coberturas vegetais e as modalidades de controle não afetaram a produtividade de silagem de sorgo, mas afetaram a de milho (Tabela 8). As maiores produtividades de silagem de milho foram obtidas após ervilhaca, tremoço e pousio com capinas e, após trigo e ervilhaca, com o uso de pós-emergente no feijão.

A renda líquida do primeiro ano agrícola foi inferior à do segundo, na maioria dos tratamentos. Isto se deve aos custos mais elevados no primeiro ano. A maior renda líquida acumulada, após duas safras, foi obtida com cobertura morta de aveia preta e controle de plantas daninhas no feijão, com o uso de um graminicida pré-emergente, seguido de capinas complementares, quando necessário (Tabela 9).

O resumo das análises de variância são apresentados nas Tabelas 10 e 11.

TABELA 8 - Produtividade $\left(t_{\text {.ha }}{ }^{-1}\right)$ de silagem de sorgo (1986/87) e de milho (1987/88) num sistema de sucessấo de culturas de inverno/feijäo/culturas para silagem. Arapoti, $\mathbf{P R}^{1}$.

\begin{tabular}{l|c|c|c|c|c|c}
\hline \multirow{2}{*}{$\begin{array}{c}\text { Culturas de } \\
\text { inverno }\end{array}$} & \multicolumn{3}{c|}{$\begin{array}{c}\text { Silagem de sorgo } \\
\text { Modalidades de controle }\end{array}$} & \multicolumn{3}{c}{$\begin{array}{c}\text { Silagem de milho } \\
\text { Modalidades de controle }\end{array}$} \\
\cline { 2 - 7 } & Cap & PE+Cap & PO & Cap & PE+Cap & PO \\
\hline trigo & A & A & A & A & A & A \\
& 44 a & 34 a & 36 a & 29 bc & 32 a & 34 a \\
aveia & A & A & A & A & A & A \\
& 38 a & 43 a & 40 a & 31 abc & 28 a & 30 ab \\
centeio & A & A & A & A & A & A \\
& 27 a & 43 a & 35 a & 24 c & 29 a & 25 b \\
ervilhaca & A & A & A & A & A & A \\
& 40 a & 33 a & 28 a & 38 a & 32 a & 34 a \\
tremoço & A & A & A & A & A & A \\
& 29 a & 32 a & 25 a & 34 ab & 31 a & 29 ab \\
pousio & A & A & A & A & AB & B \\
& 35 a & 28 a & 28 a & 36 ab & 33 a & 26 ab \\
\hline
\end{tabular}

${ }^{1}$ Médias seguidas da mesma letra, náo diferem entre si pelo teste de Tukey ao nível de $5 \%$ de probabilidade, sendo que, letras maiúsculas sobre os números, referem-se a efeitos de subtratamentos (modalidades de controle) dentro de cada tratamento (culturas de inverno) ou comparaçăo na horizontal e, letras minúsculas ao lado dos números, referem-se a efeitos de tratamentos dentro de cada subtratamento, ou comparaçāo na vertical.

${ }^{2} \mathrm{Cap}=$ capinas; $\mathrm{PE}=$ herbicida pré-emergente; $\mathrm{PO}=$ herbicida pós-emergente.

TABELA 9 - Renda líquida (US\$.ha ${ }^{-1}$ ) obtida num sistema de sucessão de culturas de inverno/feijāo/culturas para silagem. Arapoti, PR.

\begin{tabular}{l|c|c|c|c|c|c|c|c|c}
\hline \multirow{2}{*}{$\begin{array}{c}\text { Culturas } \\
\text { de inverno }\end{array}$} & \multicolumn{3}{|c|}{$\begin{array}{c}\text { 1986/87 } \\
\text { Modalidades de controle }\end{array}$} & \multicolumn{3}{c|}{$\begin{array}{c}\text { 1987/88 } \\
\text { Modalidades de controle }\end{array}$} & \multicolumn{3}{c}{ Modalidades de controle } \\
\cline { 2 - 10 } & Cap & PE+Cap & PO & Cap & PE+Cap & PO & Cap & PE+Cap & PO \\
\hline trigo & 743.38 & 598.66 & 583.89 & 731.21 & 953.23 & 812.46 & 1474.59 & 1551.89 & 1396.35 \\
aveia & 652.50 & 938.07 & 734.30 & 1019.22 & 934.07 & 910.35 & 1671.72 & 1872.14 & 1644.65 \\
centeio & 299.71 & 540.32 & 567.51 & 643.73 & 943.74 & 634.96 & 943.44 & 1484.06 & 1202.47 \\
ervilhaca & 619.97 & 497.08 & 330.00 & 1157.80 & 977.54 & 973.19 & 1777.77 & 1474.62 & 1303.19 \\
tremoço & 353.84 & 524.22 & 327.95 & 1183.38 & 974.25 & 769.68 & 1537.22 & 1498.47 & 1097.63 \\
pousio & 666.45 & 516.29 & 460.05 & 1200.63 & 1102.30 & 588.91 & 1867.08 & 1618.59 & 1048.96 \\
\hline
\end{tabular}

${ }^{1} \mathrm{Cap}=$ capina; $\mathrm{PE}=$ herbicida pré-emergente; $\mathrm{PO}=$ herbicida pós-emergentes. 
TABELA 10 - Resumo das análises de variância (quadrados médios) da safra de 1986/87².

\begin{tabular}{|c|c|c|c|c|c|c|c|}
\hline \multirow{2}{*}{$\begin{array}{l}\text { Fonte de } \\
\text { variação }\end{array}$} & \multirow[b]{2}{*}{ G.L. } & \multirow{2}{*}{$\begin{array}{l}\text { Cobertura do } \\
\text { solo pela palha } \\
\text { culturas de } \\
\text { inverno } \\
\left(20 \text { dds }^{2}\right)\end{array}$} & \multicolumn{3}{|c|}{ Controle de plantas daninhas $\left(40 \mathrm{dds}^{2}\right)$} & \multicolumn{2}{|c|}{ Produtividade } \\
\hline & & & $\begin{array}{c}\text { Brachiaria } \\
\text { plantaginea }\end{array}$ & $\begin{array}{c}\text { Sida } \\
\text { rhombifolia }\end{array}$ & $\begin{array}{c}\text { Raphanus } \\
\text { raphanistrum }\end{array}$ & $\begin{array}{c}\text { Grãos de feijâo } \\
(14 \% \mathbf{U}) \\
\left(\mathrm{kg} \mathrm{ha}^{-1}\right)\end{array}$ & $\begin{array}{c}\text { Silagem } \\
\left(t \mathbf{h a}^{-1}\right)\end{array}$ \\
\hline Bloco & 2 & 35,1680 & 40,6875 & 42,3439 & 5,0938 & 106688,0000 & 60,9082 \\
\hline $\begin{array}{l}\text { Culturas de } \\
\text { inverno (A) }\end{array}$ & 5 & $844,7686^{* *}$ & $231,8625^{* *}$ & $93,0750^{* *}$ & $513,1499^{* *}$ & 486275,1875 & 181,3633 \\
\hline Erro a & 10 & 12,8785 & 14,4688 & 13,8812 & 21,7312 & 385716,7500 & 73,8934 \\
\hline $\begin{array}{l}\text { Modalidade de } \\
\text { controle (B) }\end{array}$ & 2 & 2,0332 & $231,8125^{* *}$ & 12,5000 & $76,8125^{*}$ & 225176,0000 & 71,3457 \\
\hline Interação (A x B) & 10 & 5,4656 & $39,1062^{* *}$ & $22,9875^{\circ}$ & $59,3250^{* *}$ & 163176,0000 & 78,3457 \\
\hline Erro b & 24 & 5,7850 & 8,7604 & 9,4167 & 13,9453 & 137951,3125 & 75,8151 \\
\hline C.V. ${ }^{3} \%(A)$ & - & 11,27 & 5,69 & 5,51 & 6,95 & 34,71 & 24,68 \\
\hline C.V.\% (B) & - & 7,55 & 4,43 & 4,54 & 5,56 & 20,76 & 25,00 \\
\hline
\end{tabular}

* e* Significativo ao nível de $5 \%$ e $1 \%$ de probabilidade, respectivamente.

1 Os valores de cobertura do solo e controle de plantas daninhas foram obtidos com dados transformados em are sen $\sqrt{\mathrm{x} / 100}$.

2 Dias depois da semeadura do feijăo.

${ }^{3}$ Coeficiente de variaçăo.

TABELA 11 - Resumo das análises de variância (quadrados médios) da safra de 1987/88 .

\begin{tabular}{|c|c|c|c|c|c|c|c|}
\hline \multirow[b]{2}{*}{$\begin{array}{l}\text { Fonte de } \\
\text { variaçâao }\end{array}$} & \multirow[b]{2}{*}{ G.L. } & \multirow{2}{*}{$\begin{array}{l}\text { Cobertura do } \\
\text { solo pela palha } \\
\text { culturas de } \\
\text { inverno } \\
\left(20 \text { dds }^{2}\right)\end{array}$} & \multicolumn{3}{|c|}{ Controle de plantas daninhas $\left(40 \mathrm{dds}^{2}\right)$} & \multicolumn{2}{|c|}{ Produtividade } \\
\hline & & & $\begin{array}{c}\text { Brachiaria } \\
\text { plantaginea }\end{array}$ & $\begin{array}{c}\text { Sida } \\
\text { rhombifolia }\end{array}$ & $\begin{array}{c}\text { Raphanus } \\
\text { raphanistrum }\end{array}$ & $\begin{array}{c}\text { Grãos de feijão } \\
(14 \% \mathrm{U}) \\
\left(\mathrm{kg} \mathrm{ha}^{-1}\right)\end{array}$ & $\begin{array}{c}\text { Silagem } \\
\left(\mathrm{t} \mathrm{ha}^{-1}\right)\end{array}$ \\
\hline Bloco & 2 & $53,6115^{*}$ & $72,0825^{\circ}$ & $129,5851^{*}$ & $28,7771^{*}$ & 32911,78 & 9,5564 \\
\hline $\begin{array}{l}\text { Culturas de } \\
\text { inverno (A) }\end{array}$ & 5 & $884,1349^{* *}$ & $708,9219^{* *}$ & $147,9396^{*}$ & $2125,0000^{* *}$ & 80056,80 & 68,4524 \\
\hline Erro a & 10 & 12,4761 & 11,6356 & 29,1330 & 12,5095 & 173300,30 & 64,3974 \\
\hline $\begin{array}{l}\text { Modalidade de } \\
\text { controle (B) }\end{array}$ & 2 & $50,6740^{\circ}$ & $832,4227^{* *}$ & $448,9323^{* *}$ & $148,3620^{*}$ & $956959,80^{* *}$ & 24,7266 \\
\hline Interação (A x B) & 10 & 18,6392 & $193,2446^{* *}$ & $27,0865^{* *}$ & $47,1373^{\circ \bullet}$ & $133393,10^{\circ}$ & 27,7056 \\
\hline Erro b & 24 & 12,3161 & 19,8672 & 9,6782 & 13,5331 & 56357,11 & 16,1929 \\
\hline C.V. ${ }^{3} \%(A)$ & - & 9,23 & 5,75 & 8,85 & 6,21 & 40,72 & 25,64 \\
\hline C.V.\% (B) & - & 9,18 & 7,51 & 5,10 & 6,46 & 23,22 & 12,86 \\
\hline
\end{tabular}

* e ** Significativo ao nível de $5 \%$ e $1 \%$ de probabilidade, respectivamente.

1 Os valores de cobertura do solo e controle de plantas daninhas foram obtidos com dados transformados em are sen $\sqrt{\mathrm{x} / 100}$.

2 Dias depois da semeadura do feijáo.

${ }^{3}$ Coeficiente de variação. 


\section{AGRADECIMENTOS}

Os autores expressam agradecimentos ao Ene Age Nelson Ceregatti, da Cooperativa Agrícola de Arapoti, pela cessão da área, maquinário, insumos e pessoal de apoio; ao técnico agrícola Calos Alberto Hamanaka, do ZAPAR, pela dedicação na condução do trabalho e à Inês Fumiko Ubukata Yada, Técnica da Area de Biometria, do ZAPAR, pelas análises estatísticas.

\section{LITERATURA CITADA}

ALMEIDA, F.S. A alelopatia e as plantas. Londrina: IAPAR, 1988. 60p. (ZAPAR. Circular 53).

ALMEIDA, F.S. Controle de plantas daninhas em plantio direto. Londrina: IAPAR, 1991. 34p. (TAPAR. Circular 67).

ALMEIDA, F.S.; RODRIGUES, B.N. Guia de herbicidas: contribuição para o uso adequado em plantio direto e convencional. Londrina: IAPAR/GTL,1985.468p.

ALMEIDA, F.S.; RODRIGUES, B.N.; OLIVEIRA, V.F. Controle de plantas daninhas na cultura do feijão no Estado do Paraná. Londrina: TAPAR, 1983. 22p. (TAPAR. Circular 32).
ALMEIDA, F.S.; RODRIGUES, B.N.; OLIVEIRA, V. F. Plantio direto de milho; uso de coberturas mortas como forma de reduzir o emprego de herbicidas. In: CONGRESSO NACIONAL DE MILHO E SORGO, 15, Maceió, AL, 1984. Anais. Brasilia: EMBRAPADDT, 1986. p.277 (EMBRAPA-CNPMS. Documentos, 5).

IAPAR. Cartas climáticas básicas do Estado do Paraná, 1978. Londrina: IAPAR, 1978. 41p.

RODRIGUES, B.N.; ALMEIDA, F.S. Influência de coberturas mortas no controle de plantas daninhas na cultura do feijão. IAPAR, Relatório Interno da AHB, 1985/86.

RODRIGUES, B.N.; ALMEIDA, F.S.; SIQUEIRA, R.; FIGUEIREDO, P.R.A. Plantas daninhas e seu controle. In: IAPAR. O feijão no Paraná. Londrina, 1989. p.167-88. (IAPAR. Circular 63).

SKÓRA NETO, F. Redução da infestação do solo através da prevenção de produção de sementes de plantas daninhas na cultura do milho. IAPAR, Relatório Interno da AHB, 1992/93. 